\title{
“An Be Jigi”: Collective cooking, whole grains, and technology transfer in Mali
}

\author{
Wenda K. Bauchspies ${ }^{a \star}$, Fatimata Diarra ${ }^{\text {bc }}$, Fred Rattunde ${ }^{d}$, and Eva Weltzien ${ }^{d}$ \\ ${ }^{\mathrm{a}}$ Michigan State University, East Lansing, MI 48824, USA; ${ }^{\mathrm{b}}$ Kwame Nkrumah University of Science and \\ Technology, Kumasi, Ghana; ${ }^{c}$ ICRISAT, BP 320 Bamako, Mali; ${ }^{\mathrm{d} U n i v e r s i t y ~ o f ~ W i s c o n s i n-M a d i s o n, ~}$ \\ Madison, WI 53706, USA \\ *wkbauchspies@gmail.com
}

OPEN ACCESS

Citation: Bauchspies WK, Diarra F, Rattunde F, and Weltzien E. 2017. "An Be ligi": Collective cooking, whole grains, and technology transfer in Mali. FACETS 2: 955-968. doi: I 0. I I 39/facets-20 I 7-0033

Editor: Leland Glenna

Received: March 31, 2017

Accepted: July 20, 2017

Published: November 30, 2017

Note: This paper is part of a Collection titled "Social Dimensions of Rural African Agriculture, Food, and Development".

Copyright: (c) 2017 Bauchspies et al. This work is licensed under a Creative Commons Attribution 4.0 International License (CC BY 4.0), which permits unrestricted use, distribution, and reproduction in any medium, provided the original author(s) and source are credited.

Published by: Canadian Science Publishing

\begin{abstract}
This paper addresses how available resources, food security, technology, and culture are shaping the choices rural Malian women are making to ensure the health, energy, and well-being of their families. This research contributed to evaluating an eight-year research project (An Be Jigi) targeting improved nutrition. The study, performed over four months, used semi-structured interviews of 120 women in six villages in Mali to assess the identified issues with qualitative and quantitative approaches. This paper describes the history of the An Be Jigi project, whole-grain processing techniques, and group cooking for knowledge sharing with rural women for improved nutrition. Interviews revealed substantial adoption of whole-grain processing techniques and women's appreciation of the nutritional benefits of those techniques. The women engaged in group cooking (cuisines collectives) appreciated the activities and mentioned multiple benefits from using them. Women identified access to mills, and to some extent the social stigma of laziness and poverty associated with whole-grain food, as limiting factors of adoption. This study of women's practices and perceptions regarding use of whole grain tells a story of changing consumption habits being shaped by culture, technology, knowledge, and available resources. Malian women are agents of change and care in their adoption of new techniques and recipes for the improved nutrition of young children and households.
\end{abstract}

Key words: whole grains, decortication, collective cooking, An Be Jigi, technology adoption, technology transfer, sorghum, millet, agriculture, Mali

If science is not crafted to address the local character of farming places and practices, then growers are unlikely to accept the research-based advice of advisors.

$$
\text { -Henke (2000, p. 485) }
$$

\section{Background and introduction to the An Be Jigi project}

The McKnight Foundation ${ }^{1}$ funded the An Be Jigi project ("Hope for all" in Bambara), to improve the micronutrient nutrition of young children and their mothers through sustainable biofortification of sorghum and millet, traditional staple cereals, by building on farmers' knowledge and ongoing participatory breeding activities. The project ran in two major sorghum producing areas

${ }^{1}$ The Foundation's Collaborative Crops Research Program (CCRP) supported a series of synergistic projects with the An Be Jigi, ALIVE Legume Intensification, and Seed System projects forming part of the CCRP Western Africa Community of Practice. 
of Mali in the Koulikoro region from 2006 to 2015. The team tested and promoted different options for improving the contribution of sorghum and millet to the micronutrient nutrition of children and women of child-bearing age. Helen Keller International (HKI) led the collaborative activities with contributions by the International Crops Research Institute for the Semi Arid Tropics (ICRISAT) and l'Institute d'Economie Rurale (IER), the Union Locale des Producteurs de Cereales (ULPC) in the Dioila area, and the Association des Organisations des Producteurs Professionelles (AOPP) in the Siby area.

The An Be Jigi project started with a Baseline Nutrition Survey ${ }^{2}$ in 2006 that indicated high levels of malnutrition and low growth and weight gain in children, as well high levels of anemia in the targeted communities (Mahy et al. 2007a) that were comparable to the anemia prevalence for children aged 6-59 months (81\%) and women (43\%) reported at the national level in the Enquête Démographique et de Santé du Mali 2006 (CPS/MS et al. 2007). A food-consumption survey of children (between 12 and 24 months) and their mothers with 24-h direct consumption observations and quantitative measures (53 households) on two non-consecutive days (11 households) was conducted by the project in May (dry season) and August (hunger period) 2008. The survey revealed that although rice and sorghum were the cereals most frequently consumed, sorghum and millet together accounted for more than $50 \%$ of cereal quantities consumed by children and their mothers in both time periods (Smit et al. 2008). Sorghum and pearl millet were estimated to constitute at least $50 \%$ of daily iron and $65 \%$ of zinc intake for children and their mothers. Recognizing the current role of sorghum and millet for micronutrient nutrition, the project team focused on improving the bioavailability of iron and zinc of these cereals to positively contribute to the nutrition of children and women of child-bearing age in this region (Smit et al. 2008; Tuinsma et al. 2011).

The An Be Jigi team tested the importance of varietal differences, the diversity of growing conditions, and the consequence of local grain processing procedures on sorghum $\mathrm{Fe}$ and $\mathrm{Zn}$ availability to improve intake and bioavailability. The testing was done through annual food quality evaluations conducted by a participatory sorghum breeding program (Debrah et al. 1996; Weltzien et al. 2008). Although varietal differences and growing conditions were found to significantly affect Fe and Zn concentrations, a major factor determining micronutrient availability was how women processed the grain to produce flour. The decortication of sorghum (pounding grain to remove the seed coat) resulted in an approximately $50 \%$ loss of $\mathrm{Fe}$ and $\mathrm{Zn}$ when producing flour; a result confirmed by more detailed studies (Hama et al. 2011). Thus, although the original challenge was to identify sorghum varieties with high $\mathrm{Fe}$ and $\mathrm{Zn}$ concentrations, a new challenge with a more immediate and potentially greater impact was to find a locally acceptable method for processing sorghum grain without decortication. The Baseline Nutrition Survey noted that:

"Decortication is a common practice in the three zones, with all women decorticating the sorghum and $88 \%$ of women decorticating the millet. The majority of the women indicated (that they know how to) ... use the method of malting ${ }^{3}$ of sorghum or millet before preparation." -Mahy et al. 2007a, p. vi

\footnotetext{
${ }^{2}$ The survey was completed with 150 households (mothers and household heads) in the zones of Mandé, Dioila, and Ténenkou. The households were interviewed about their socio-economic status, food security, child health, hygiene, cultivation, and food consumption. In addition, blood, urine, and faeces samples were collected and analysed for haemoglobin levels and the presence of intestinal parasites (Mahy et al. 2007a).

${ }^{3}$ Malting is used to increase the starch solubility of sorghum flour and the energy density of the food made from malted flour (Ashworth et al. 1992). The term typically used in these communities for malting implies fermentation, which also has religious and cultural taboos associated with it.
} 
A method of producing whole-grain sorghum flour without decortication was developed by the project team (Tuinsma et al. 2011). By soaking cleaned grain for $8 \mathrm{~h}$, sun-drying sufficiently to enable milling, and then using privately operated mechanical mills, whole-grain flour could be produced in rural villages in Mali. ${ }^{4}$ The nutritionists involved expected this procedure to give higher concentrations of $\mathrm{Fe}$ and $\mathrm{Zn}$ in the final product, and possibly increase their bioavailability through enzymatic breakdown of the Fe- and Zn-binding phytate during the soaking period (Platel and Srinivasan 2016).

\section{Collective cooking sessions}

The An Be Jigi team conducted group-based training and evaluation workshops with mothers of young children in local health centers. This training built upon prior group variety evaluation activities to address child nutrition and joint learning about grain processing methods. In the second phase of the project, the team worked with village-level mothers' groups on nutrition training, sorghum processing, and testing new recipes. To facilitate the process, pictorial information "books" were prepared by the An Be Jigi team to share both health and nutritional information.

The An Be Jigi project began sponsoring "cuisines collectives" (group cooking sessions) ${ }^{6}$ in 2013. Cuisines collectives are an adaptation of farmer field schools ${ }^{7}$ that the ICRISAT and IER sorghum breeding teams, together with development partners, had been using for facilitating farmer experiential learning. The project hosted cuisines collectives in the six project villages ${ }^{8}$ of An Be Jigi to demonstrate the procedure of soaking and milling whole grains and introduce new recipes for using whole grain flour. It is estimated that 33 cooking demonstrations reached 535 individuals in six villages during the life of the project (Rattunde et al. 2014). Several communities reported to the An Be Jigi team that women had begun organizing their own cuisines collectives on a weekly or monthly basis after participating in the An Be Jigi group cooking session.

This study (i.e., the An Be Jigi adoption study detailed below) was designed in 2014 to gain insights from women who had participated in An Be Jigi-sponsored cuisines collectives. The team wanted to determine:

\footnotetext{
${ }^{4}$ Soaking involved placing the cleaned and washed grain in just enough water to be fully absorbed (minimizing the loss of iron or zinc in excess water), soaking for at least $8 \mathrm{~h}$, and then drying the grains on a clean, well-aerated surface until the grain surface was dry. The soaked and dried whole grains can be directly ground in a mill to produce flour for use in traditional and new recipes. With this process, whole grain flour can be produced that is as fine and smooth as flour prepared from traditionally decorticated grain. In contrast, whole grain flour production with a mortar and pestle is difficult and the resulting flour has an irritating mouth-feel (Scheuring et al. 1983; Elkhalifa et al. 2005). The new recipe, promoted as a weaning food for young children, included the addition of vitamin $\mathrm{C}$ from lemon juice, baobab powder, or tamarind to improve micronutrient bioavailability, as well the optional addition of cowpea or soy flour for improved protein nutrition (Mahy et al. 2007b). The production of malt follows the same soaking process but the grain is kept in a basket and enclosed in a "boro" cork bag for 24-72 h before surface drying and grinding in a mill. The flour from ground malt can be used in traditional and new recipes.

${ }^{5}$ In addition to being engaged in educational activities focused on nutrition and processing cereals through the An Be Jigi project, women were also doing evaluations of new sorghum varieties in their own fields with the project (ICRISAT 2015). They identified the preferred varieties that included those with highest Fe and Zn concentrations, and learned how to produce seeds for their own use.

${ }^{6} \mathrm{~A}$ cuisines collectives or group cooking session would be organized by the local facilitator in a community space that offered shade and space to set up three to four cooking fires. This may be at the local health clinic, someone's home, or a communal space within the village. The facilitator would ensure that there was sufficient firewood for cooking, large pots, fire circles, ingredients, serving dishes, and water. Fifteen to twenty women would gather at the appointed time to observe a demonstration, cook together, and evaluate the techniques. The purpose was to learn from the demonstration, to test the techniques and resulting food, and to compare assessments with the group.

${ }^{7}$ Please see Simpson and Owens' (2002) overview of Farmer Field School adoption in Africa as an extension practice to engage smallholder farmers in knowledge-building activities.

${ }^{8}$ Siby, Bancoumana, Kéniéro, Wacoro, N’Golobougou, and Séribila.
} 
1. Women's perceptions about the acceptability of grain processing methods.

2. The acceptability of the new recipes that were introduced by the project to the women and their families.

3. To identify why women chose to adopt techniques and recipes for the use of whole grain sorghum for feeding their children, family, or themselves.

"Anyway, I'm glad you're here. In my time we were all healthy, we rarely got sick and we were very strong. All this was due to the fact that we ate well."

-Grandmother, age 62, in Bancoumana, Mali, 10 September 2014.

\section{The An Be Jigi adoption study}

Focus groups and semi-structured interviews were conducted for this study in six Malian villages: Siby, Bancoumana, Kéniéro, Wacoro, N'Golobougou, and Séribila. ${ }^{9}$ The questionnaire was designed by a social scientist of gender and technology in consultation with ICRISAT research assistants and plant breeders, and was translated from French into Bambara by an ICRISAT research assistant fluent in both languages. The semi-structured questionnaire was tested for clarity and understandability in Bambara in a pilot study with six participants and subsequently modified to ensure coherence of questions and answers. The interviewer for both individual and group interviews was a native speaker of Bambara, the lingua franca of all six communities.

Participants provided informed consent at the beginning of the study in addition to indicating if they wanted to keep their name confidential or to allow the study to quote them by name. ${ }^{10}$ The questionnaire asked basic demographic information that included age, family situation, education, and number of children. The study objectives were explored in 11 questions designed to elicit answers about women's adoption of processing methods, recipes, and techniques, as well as why they have or have not adopted the techniques along with their experiences that identified factors contributing to adoption or non-adoption. The guide for focus group discussions was based upon the semi-structured individual questionnaire but modified to accommodate a group of four to five women. Notes were taken in French during interviews and elaborated upon after the interview or focus group. The interview data were coded to identify what women perceived as the benefits, challenges, and trade-offs of the adoption of whole grain processing and cooking.

The village chiefs were informed of the project's activities and had previously granted permission for the project to be active in the village. The local An Be Jigi contact person and local facilitator in each village introduced the interviewer to the president of the cooperative participating in the project activities. The president of the cooperative invited women who had previously attended cuisines collectives to participate in a focus group regarding topics touched on in the cuisines collectives. All women who showed up to participate in the focus groups indicated their willingness to participate voluntarily by both their presence and verbal agreement. ${ }^{1}$

\footnotetext{
${ }^{9}$ The An Be Jigi project was already active in these six villages. Three of these villages were among the original six villages where the An Be Jigi Baseline Survey was administered eight years previously: Bancoumana, Kenièro, and Seribila. During the lifetime of the project, village participation shifted due to staffing, community engagement, and feasibility issues.

${ }^{10}$ Women who indicated that we could identify them are named in the paper; otherwise quoted participants are identified only by age and village.

${ }^{11}$ This process of informed consent respected the community's norms.
} 


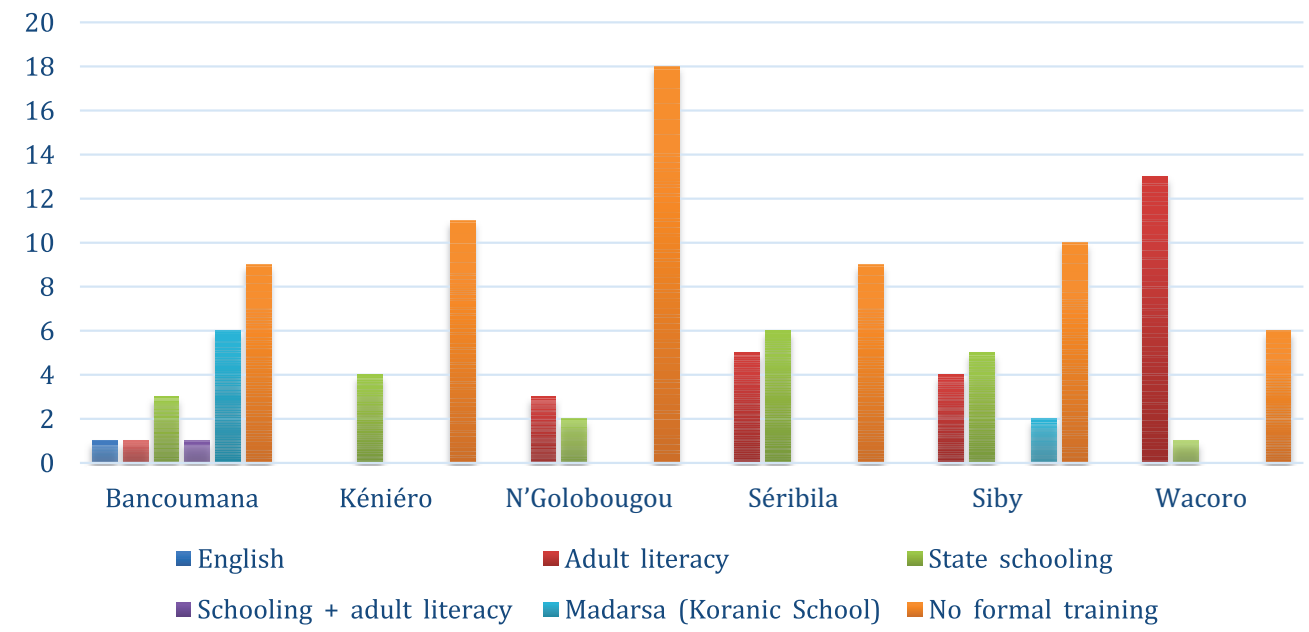

Fig. 1. Distribution of women by village and their education levels $(N=120)$.

A total of 120 women, approximately 20 women per village, ${ }^{12}$ were interviewed for the study. The women's ages ranged from 19 to 69 years. All of the interviewed women came from the region, and most had at least one child below the age of five years. The majority of the women interviewed had no formal education, with only $17 \%$ indicating having attended state schools and $6 \%$ having attended Madarsa (Koranic Schools), whereas $21 \%$ had participated in adult literacy classes (Fig. 1). The An Be Jigi project, sensitive to the low literacy rates of women in these communities, had provided education materials in pictorial form taught by individuals fluent in Bambara.

Women's roles in Mali are typically centered on the home and family, which means cooking, gardening, doing laundry, educating children, and caring for the elderly, as well as other rural activities such as gathering water and wood for household consumption and farming activities. One scholar has described Malian women as "ingenious workers who make ends meet at home" (Diallo 2009, p. 117).

Each village was visited at least twice during the course of the adoption study. Visits by the interviewer coincided with pre-scheduled cuisines collectives, to observe and participate in them as well as to interview the women participating. During the cuisine collective, the interviewer was a participant-observer and engaged in the discussion and activities of the session. The focus group organized by the president of the cooperative was composed of women from the previous day's cuisine collective. Women who indicated that they preferred to talk with a researcher on an individual basis were interviewed alone, as well as some women who had not attended the most recent cuisine collective but were recommended by someone in the focus group. Any woman who had participated in a cuisine collective and indicated interest in being interviewed one-on-one was interviewed. Women who had not participated in a cuisine collective but had learned about the techniques and recipes were identified from both one-on-one interviews and focus groups. These women were contacted by the interviewer, and if she agreed, the researcher interviewed her. The researcher identified 14 women using this snowballing technique. The majority of women interviewed had participated directly in cuisines collectives. Twelve percent of those interviewed had learned about techniques and recipes from someone else who had participated.

\footnotetext{
${ }^{12}$ This study adhered to the Principles of Professional Responsibility of the American Anthropological Association adopted November 2012. The study was reviewed and approved by ICRISAT in accordance with their agreement with the Republic of Mali, Spring 2014.
} 


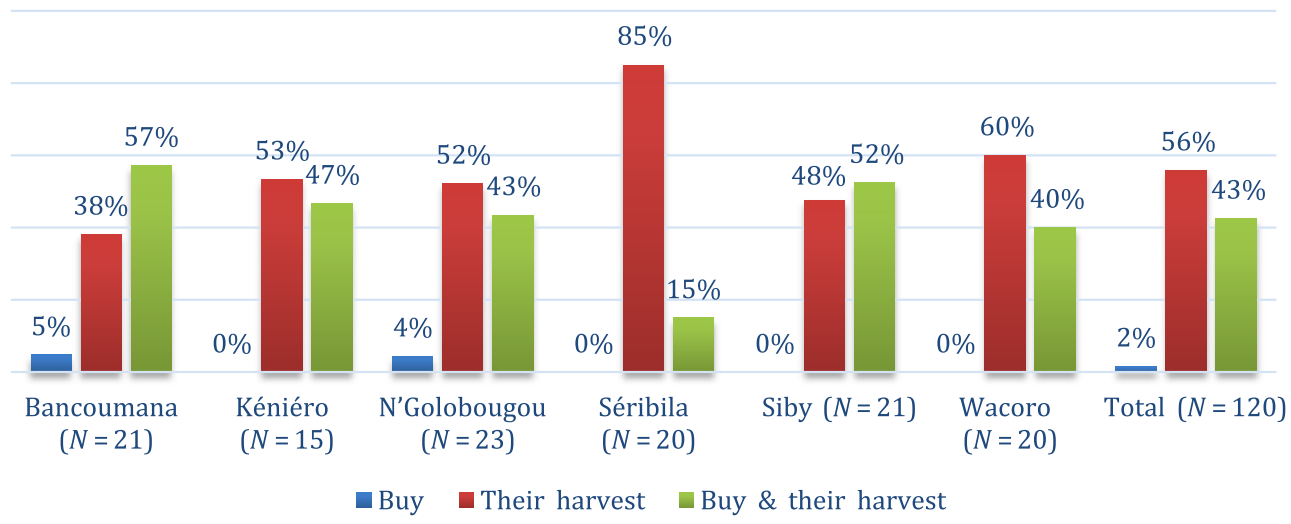

Fig. 2. Origin of the grain consumed in each village according to women's indication of how they obtain their grain.

In the following sections, we focus on the role of sorghum and millet in the community, cuisines collectives, and factors shaping the adoption or not of soaking and malting whole grains.

\section{Sorghum and millet}

Historically, the typical meal in these villages has been based upon sorghum and millet (Hatløy et al, 2000; Platel and Srinivasan 2016). Among the women interviewed for this adoption study, 56\% said they consumed only what they grow and another $43 \%$ stated that they are buying grain during the year to supplement their stock (Fig. 2). The proportion of women indicating that they depended entirely on their own harvest for grain consumed ranged from $38 \%$ to $85 \%$ across the six villages.

The An Be Jigi project introduced these innovative and new techniques for processing and consuming whole grains of sorghum and millet into a community where the current practice was to decorticate grain (see FAO 1995 for a description of traditional processing methods). One woman in Seribila referred to eating whole grains as something that was done in the past. She stated that during her childhood it was more common to eat whole grains. Several other women in the survey also referred to eating whole grains as a practice done in the past. If this is so, the historical trends and reasons for the decreased consumption of whole and fermented grains is a topic for further research. However, mechanical mills have appeared in the communities during the life spans of the women who remember eating whole grains in the past. The adoption of mechanical mills may have been a factor that contributed to the shift in cuisine practices that the women described.

When asked about the use of whole grains in their community, two women spoke of community disapproval as one of the obstacles that prevented their use of whole grains on a regular basis. "Social stigma is a big barrier to eating wholegrain", according to Aminata Sanogo from N'golobougou, Mali, who was trained by food technologists from the Malian National Agricultural Research Institute, IER (Institut d'Economie Rurale). She explained that "If you leave the bran on the grain you must be really poor as you are eating whatever you can" (CCRP 2015). A family of limited resources may collect the bran produced by the decortication process from local mills or in their neighborhood. ${ }^{13}$ In addition, the bran is used for animal feed. A local mill owner explained that he would sell bran for animal feed to extend the profit from the mill. Thus, bran has a dual use as both animal feed and food for the very poor.

\footnotetext{
${ }^{13}$ There is a local recipe to prepare hulls with shea butter and soumbala (two readily available ingredients in the village).
} 
The food yield is expected to directly increase by avoiding decortication losses (typically $10 \%-40 \%$ ) (Scheuring et al. 1983). The frequent use of whole grains during moments of household hardship can be expected to reinforce the cultural understanding that whole grains are only for those enduring hardship and poverty. During the hungry period, ${ }^{14}$ when stocks are low and before the new harvest is ready, it was normal to eat whole grains to benefit from the larger quantity of food produced from the same amount of grain. In several of the villages, the owners of the mills confirmed that during the hungry period more customers bring whole grain than decorticated grain to the mechanical mill to be ground.

A woman in Kéniéro noted that when she lacked help in the kitchen or fields, and when she was short on time to prepare a meal, she would often use the entire grain. She said that it takes less work to clean whole grain than to decorticate it by pounding. Food prepared with the decorticated grains can be whiter with less shading of color from the seed coat that is removed as bran during decortication. Most interviewed women referred to the whole grain tô ${ }^{15}$ by its local name, "Fassaman tô", which means the tô of the lazy. Names are signs (Lakoff and Johnson 1985), and the name of fassaman tô appears to affirm cultural beliefs associated with cooking the whole grain. These beliefs are then transferred to the cook by defining her as lazy or weak. Names and their associated beliefs become naturalized by frequent use, and eventually the reasons behind the values are forgotten (Bowker and Star 2008), such that no one questions why whole grain food implies that a woman is lazy.

The introduction or reintroduction of knowledge or technology into a community requires that extension agents, researchers, or development workers take existing socio-cultural meanings and representations into account. The majority of the women interviewed in this study identified no overarching difficulty with using whole grains. However, eight of the women noted sociocultural reasons related to community or family members' assessment of the whole grain food for their difficulty in adopting the technique. For example, family members who refused to eat dishes prepared with whole grain were reproducing cultural norms that associated whole grains with hardship or a lazy wife. Even though only a small portion of women indicated that family members resist eating foods prepared with whole grains, the importance of the cultural stigma of whole grains as supported by its name, Fassaman tô, warrants attention when promoting or tracking adoption.

"Framing and boxing limit experience, shut in desired themes or shut out intruding ones."

-Douglas 1991, p. 63

\section{Cuisines collectives in practice}

In the central region of Mali where the survey was done, large family size is the norm and cooking is done collectively (Toulmin 1986; De Groote and Coulibaly 1998). Typically, cooking collectively takes two forms: (1) a large family with several adult women who will rotate who is in charge of meal preparation, and (2) instances where large quantities of food are required and preparation is coordinated by a women's group. An example of the latter is preparing food for a community or family gathering such as a birth, marriage, or death. When women share the family cooking responsibility in a large household, it may be with five to 10 other women. They use a rotation system to assign who is in charge of cooking on which days.

\footnotetext{
${ }^{14}$ Depending on the location, rainfall, family resources, and time of planting, the hungry period can occur from June until September.

${ }^{15}$ Tô is a predominant local dish (sometimes called thick porridge in English) made from flour of millet, sorghum, rice, or maize.
} 
A woman in a very large household, trained in whole grain usage, may only end up being in charge of cooking every $10 \mathrm{~d}$ or so. If this is the case, the family may only be consuming whole grains three times a month if she is the only one who has adopted the techniques for whole grain cooking. In several instances, a woman explained that there were two or three women in the same family who had adopted cooking with whole grain for the entire family and not just for young children. In this case, they may only prepare whole grains from time to time for the entire family while they consume it more frequently because of other women in their household who prepare it.

The An Be Jigi project took advantage of both the strong culture of women's groups and ongoing engagement of families on a village level for sorghum variety field and cooking evaluations, to offer trainings through organized cuisines collectives. These cuisines collectives were typically held once or twice a month with women from different families in the village for learning grain processing techniques, new recipes, and nutrition facts. This forum provided women the chance to discuss concerns or ask clarification questions about the whole grain usage and general nutrition issues.

An unintended consequence of the cuisines collectives was that some women reported discussing education, child nutrition, and marital problems with other participants during the session. One participant of a cuisine collective said that she found "attentive ears" for her concerns and realized that she was not alone in her situation. Another woman reported being more informed and united by the activity. She said it translated into an increased self-confidence. Work in the UK on community gardening shows a similar pattern of therapeutic learning where participants have had new insights about themselves by participating in shared gardening and then transfer these new skills into new situations (Liu et al. 2017).

Although the adoption study targeted younger women of child-bearing years, all women were welcome. A total of 35 women over the age of 40 were interviewed. Older women showed strong interest in attending the cuisines collectives; perhaps they have more availability to participate. When asked with whom they shared the newly acquired knowledge, women often described sharing what they learned at the cuisines collectives with their daughters. Daughters-in-law were not mentioned by these women, even though they typically lived together in the same household. This limitation of communication between mothers-in-law and daughters-in-law is part of the cultural rules that define their relationship and was to be expected (White et al. 2013). Women from all age groups showed interest in attending the cuisines collectives. Their participation provided new opportunities for the exchange of knowledge, relationship, and techniques.

\section{Adoption of techniques}

Twenty-seven percent of the women said they were feeding their children (ages six months to five years) whole grain porridge every day. A total of $71 \%$ of the women interviewed reported using whole grains for feeding their children either every day or sometimes. Use of whole grains for meals given to the entire family was slightly lower at $56 \%$. However, when cooking for holidays or other large events the women said they preferred using whole grain recipes because of the increased volume of food. Women reported adopting the whole grain techniques because of time savings and decreased workload. Only a few women noted cultural values as an obstacle to adoption.

Among the woman interviewed, $83 \%$ preferred the soaking method over malting for producing whole-grain flour and were practicing it on a regular basis. A woman in Bancoumana said that soaking "does not require much time, it is easy and fast. Indeed, ... it is a technique that requires very little effort and allows me to do several other things without worrying about the next step". Some women who practice soaking found it difficult to manage the $8 \mathrm{~h}$ soaking time. They told of three main strategies to measure the soaking time; beginning the soaking in the morning and ending at 
the third prayer of the day (1600), soaking overnight, and checking the grains from time to time and ending when the grain texture was correct.

As for the malting technique, one woman in Siby described it as "complex and meticulous" because the technique involves several steps and it requires vigilance to monitor the germination process. Women mentioned that because of their workload in the family and in the field, it was difficult for them to devote time and resources to the malting technique.

"I started consuming whole grains long before the arrival of the project because I was tired of decorticating the grains. After a while I realized that my children and I were falling ill less often."

-Fanta Keita, 30 years old, 8 August 2014 in Siby

When asked why they use whole grains the most frequent response given was that it is rich in vitamins and minerals (Fig. 3). They recounted stories like the quote above from Fanta Keita to explain what they saw as a difference in their own health and that of their children from eating whole grains. Other reasons included the pleasant taste, economic benefits, and the health of pregnant women, as well as the increased energy and health of the entire family (Fig. 3). Participants of one cuisine collective noted how this new procedure reduced the time required for preparing flour from sorghum grain because it avoided the time-demanding traditional manual decortication. They also noted that it produces more flour from a given quantity of grain because there were no weight losses due to decortication.

The largest challenge to adoption that women named was access to a local mill (Fig. 4). Five of the six villages in this study had mills. A woman's available resources and her judgment on how to best use them shaped whether or not she would decorticate the whole grain manually in a mortar and pestle

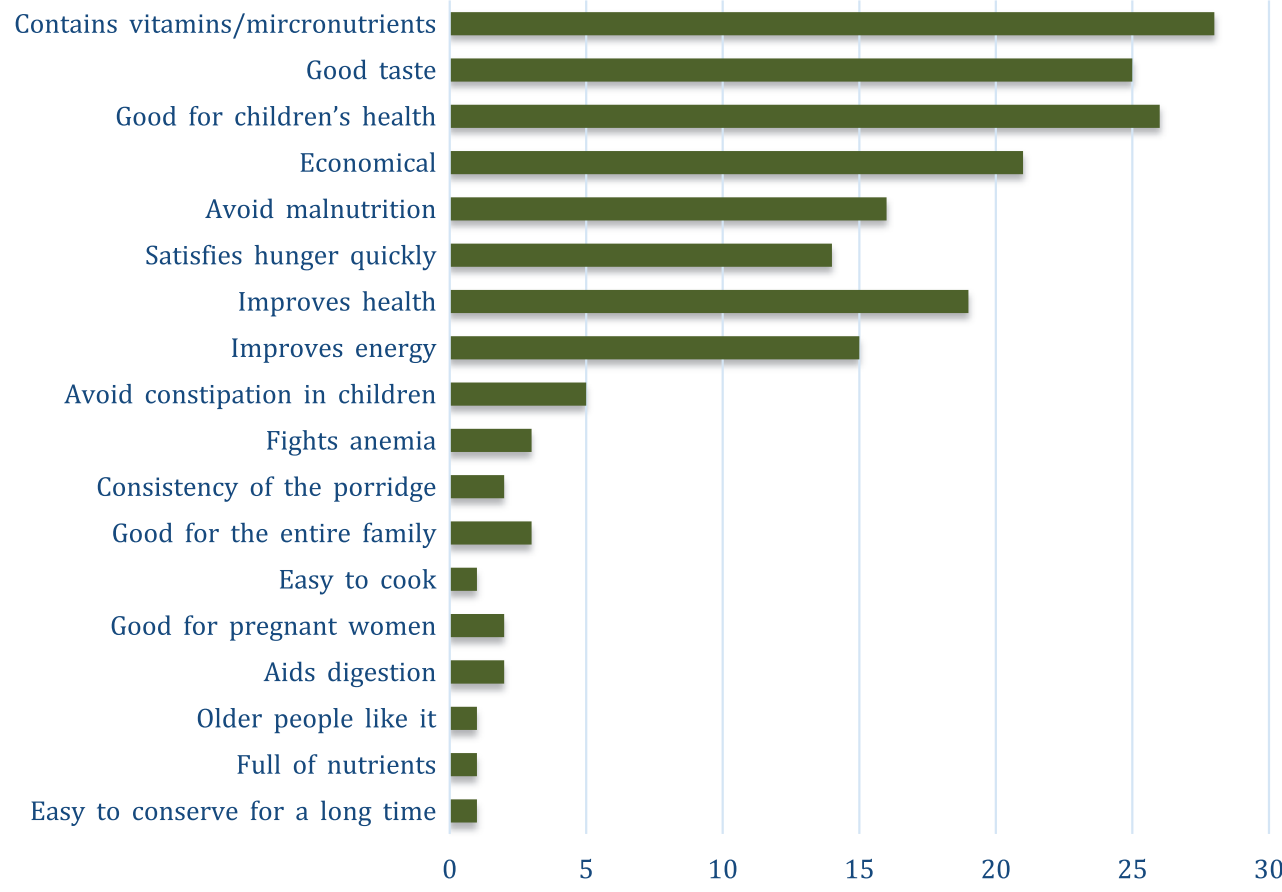

Fig. 3. Number of women identifying specific advantages of using whole grains $(N=120)$. 


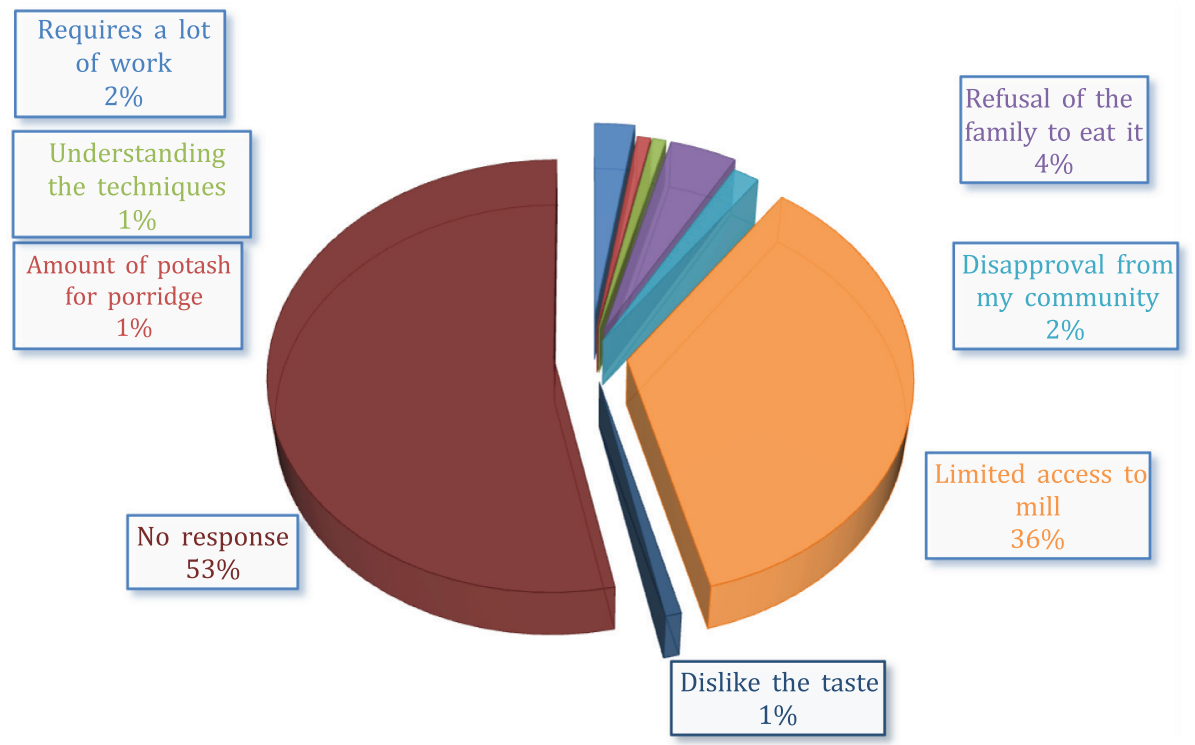

Fig. 4. Types of difficulties identified by women for using whole grains $(N=120)$.

or at the local mill. The distance to the nearest mill was cited as a discouragement for using whole grains in two of the six villages. One woman explained that if she wanted to use a motorcycle to take her grain to the mill, she would have to wait until a male household member was free to take her to the mill and back. She described how few men are available and willing to go to the mill unless there is a special occasion such as a holiday, wedding, or large community gathering. Women's access to and use of technologies such as motorcycles, in this region of West Africa, is often controlled by gendered norms that associate certain forms of western technology with men (Bauchspies 2000).

Technological adoption can have unintended consequences (Volti 2010). One mill owner whose clientele had adopted grinding whole grain told how his profits had decreased as he had previously sold the bran to cattle breeders. Now without bran for sale, he increased the prices for milling whole grains to cover his lost revenue.

\section{Conclusions}

It has been argued that cereals are humanity's double-edged sword because they were the beginning of our using "complex cultural and technological innovations" to change our world (Cordain 1999, p. 60), and those changes have had both positive and negative consequences. This paper illustrates that women are using cultural and technological innovations to change the way they are feeding their families. It also hints at both the complexity of those cultural and technological innovations and the cultural meanings that are embedded in these indigenous cereals. Historically, the communities produced and ate sorghum and millet; crops that were in part domesticated by their distant ancestors. Now, however, maize is widely consumed like sorghum and millet. Food consumption habits change over time; they are dynamic and emerge from the culture (Wallendorf and Reilly 1983; Bobrow-Strain 2008). What cultural, economic, and agronomic changes are embedded in these current shifts? One possibility hinted at from the interview data is that development work in agriculture is helping to valorize the use of the traditional grains over the newcomers, rice and maize (Jeffreys 1963). This valorization is occurring with the development of new varieties, new techniques, and new forms of dissemination such as farmer field schools. 
Overall, our interview results indicated good acceptability of the information and techniques learned in cuisines collectives, and suggested why women are adopting the use of the whole grain and the new recipes. This tells a story of changing consumption habits, as illustrated by the older women remembering that they used to eat whole grains, or the women choosing to adopt the new technique for whole grain use because of decreased work and increased nutritional benefits. A woman's choice to serve whole grains or decorticated grains may require her to negotiate cultural values and assumptions about Fassaman tô, as well as her own resources of time, food stocks, social networks, knowledge, and technology. It is an illustration of what Puig de la Bellacasa (2015, p. 694) describes as the "restless temporal regime, [which] although dominant" is not the only one. The women's responses to our questions allow us to see the care that women are taking to maintain and develop their interdependent human-food relations (Puig de la Bellacasa 2015), and how the cuisines collectives facilitate exchanges among women on such subjects.

The social solidarity for the adoption of new techniques may be strengthened by collective cooking or neutralized by cultural norms between mother-in-law and daughter-in-law relationships. Whole grain usage is shaped by considerations of the health of the children, cultural beliefs, available resources, and access to information and mills. Cultural norms, social networks, and access to knowledge impact and influence whom may be eating whole grain, and when, and where. Malian women are agents of change and care, as they negotiate complex choices to adopt or not, and when to adopt the new grain processing techniques and recipes.

\section{Acknowledgements}

The authors would like to thank the McKnight Foundation, Helen Keller International, ICRISAT, and IER for their support of the An Be Jigi project in Mali from 2006 to 2014, and the CGIAR Dryland Cereals CRP from June to September 2014 during data collection. The contributions of the nutritionists Lina Mahy, Marjolein Smit, and Vera Lugutuah for nutrition input and developing the process for whole-grain flour production, and Vera Lugutuah for developing and testing new recipes and group work with village women is highly appreciated. In addition we would like to thank the anonymous reviewers for their suggestions, patience, time, and expertise.

\section{Author contributions}

WKB, FR, and EW conceived and designed the study. FD performed the experiments/collected the data. WKB and FD analyzed and interpreted the data. FR and EW contributed resources. WKB, FR, and EW drafted or revised the manuscript.

\section{Competing interests}

WB served as a Guest Editor for this Collection, but was not involved in review or editorial decisions regarding this manuscript.

\section{Data accessibility statement}

All relevant data are within the paper.

\section{References}

Ashworth A, Draper A, and World Health Organization. 1992. The potential of traditional technologies for increasing the energy density of weaning foods: a critical review of existing knowledge with particular reference to malting and fermentation. World Health Organization, Geneva, Switzerland [online]: Available from who.int/iris/handle/10665/61642. 
Bauchspies WK. 2000. Cultural re-constructions of an adoptive child: science. Cultural Dynamics, 12(2): 237-260. DOI: 10.1177/092137400001200207

Bobrow-Strain A. 2008. White bread bio-politics: purity, health, and the triumph of industrial baking. Cultural Geographies, 15(1): 19-40. DOI: 10.1177/1474474007085783

Bowker GC, and Star SL. 2008. Sorting things out: classification and its consequences. MIT Press, Cambridge, Massachusetts.

Cellule de Planification et de Statistique du Ministère de la Santé (CPS/MS), Direction Nationale de la Statistique et de l'Informatique du Ministère de l'Économie, de l'Industrie et du Commerce (DNSI/MEIC) et Macro International Inc. 2007. Enquête Démographique et de Santé du Mali 2006. CPS/DNSI et Macro International Inc., Calverton, Maryland.

Collaborative Crop Research Program (CCRP). 2015. Enhancing bioavailability of iron and zinc in varieties of sorghum and pearl millet consumed in Mali. The McKnight Foundation, Minneapolis, Minnesota. ccrp.org/projects/be-jigi-ii.

Cordain L. 1999. Cereal grains: humanity's double-edged sword. World Review of Nutrition and Dietetics, 84: 19-73. PMID: 10489816

De Groote H, and Coulibaly N. 1998. Gender and generation: an intra-household analysis on access to resources in southern Mali. African Crop Science Journal, 6(1): 79-96. DOI: 10.4314/acsj.v6i1.27827 [online]: Available from hdl.handle.net/1807/22729.

Debrah SK, Sanogo D, and Boadu FO. 1996. On-farm experiments with sorghum to assess the acceptability of new varieties and herbicide treatments. Experimental Agriculture, 32(2): 219-223. DOI: $10.1017 /$ S0014479700026120

Diallo A. 2009. Women in the back seat in Malian citizenship. In Body politics and women citizens: African experiences. Sida Studies. Edited by A Schlyter. Swedish International Development Cooperation Agency, Stockholm, Sweden. Vol. 24, pp. 115-124. ISBN 978-91-586-4100-6.

Douglas M. 1991. Purity and danger: an analysis of the concepts of pollution and taboo. Routledge, London, UK.

Elkhalifa AEO, Schiffler B, and Bernhardt R. 2005. Effect of fermentation on the functional properties of sorghum flour. Food Chemistry, 92(1): 1-5. DOI: 10.1016/j.foodchem.2004.05.058

Food and Agriculture Organization (FAO). 1995. Sorghum and millets in human nutrition: traditional processing methods. FAO Corporate Document Repository [online]: Available from fao.org/ docrep/t0818e/T0818E09.HTM.

Hama F, Icard-Vernière C, Guyot J-P, Picq C, Diawara B, and Mouquet-Rivier C. 2011. Changes in micro- and macronutrient composition of pearl millet and white sorghum during in field versus laboratory decortication. Journal of Cereal Science, 54(3): 425-433. DOI: 10.1016/j.jcs.2011.08.007

Hatløy A, Hallund J, Diarra MM, and Oshaug A. 2000. Food variety, socioeconomic status and nutritional status in urban and rural areas in Koutiala (Mali). Public Health Nutrition, 3(1): 57-65. PMID: 10786724 DOI: $10.1017 /$ S1368980000000628

Henke CR. 2000. Making a place for science: the field trial. Social Studies of Science, 30(4): 483-511. DOI: $10.1177 / 030631200030004001$ 
ICRISAT. 2015. International Women's Day Special: changing the fate of Malian children around a cooking pot. Happenings: ICRISAT In-house Newsletter, 6 March 2015, no. 1665 [online]: Available from icrisat.org/newsroom/latest-news/happenings/happenings1665.htm.

Jeffreys MDW. 1963. How ancient is West African maize? Africa, 33(2): 115-131. DOI: 10.2307/ 1158283

Lakoff G, and Johnson M. 1985. Metaphors we live by. University of Chicago Press, Chicago, Illinois.

Liu P, Gilchrist P, Taylor B, and Ravenscroft N. 2017. The spaces and times of community farming. Agriculture and Human Values, 34(2): 363-375. DOI: 10.1007/s10460-016-9717-0

Mahy L, Lingle K, Traore S, Sidibe CS, Rattunde F, and Smit M. 2007a. Nutrition baseline report for An Be Jigi; use of local diversity for enhancing nutrition (especially $\mathrm{Fe} / \mathrm{Zn}$ bioavailability) in sorghum/pearl millet consuming communities. Internal Report, Helen Keller International, Institut d'Economie Rurale (IER), McKnight Foundation, and ICRISAT, Bamako, Mali.

Mahy L, Lingle K, Traore S, Sidibe CS, Rattunde F, and Smit M. 2007b. An Be Jigi; use of local diversity for enhancing nutrition (especially $\mathrm{Fe} / \mathrm{Zn}$ bioavailability) in sorghum/pearl millet consuming communities [online]: Available from ccrp.org/projects/be-jigi-i.

Platel K, and Srinivasan K. 2016. Bioavailability of micronutrients from plant foods: an update. Critical Reviews in Food Science and Nutrition, 56(10): 1608-1619. PMID: 25748063 DOI: 10.1080/ 10408398.2013.781011

Puig de la Bellacasa M. 2015. Making time for soil: technoscientific futurity and the pace of care. Social Studies of Science, 45(5): 691-716. PMID: 26630817 DOI: 10.1177/0306312715599851

Rattunde F, Rattunde EW, Sidibe CS, Grant F, Ouolouguem B, and Diarra H. 2014. 10-140, 10-581, 10-582_Year 3 2013_An Be Jigi II enhancing bioavailability of iron and zinc in varieties of sorghum and pearl millet consumed in Mali [online]: Available from ccrp.org/node/1261.

Scheuring JF, Sidibe S, Rooney LW, and Earp CF. 1983. Sorghum pericarp thickness and its relation to decortication in a wooden mortar and pestle. Cereal Chemistry, 60: 86-89 [online]: Available from oar.icrisat.org/5553/.

Simpson BM, and Owens M. 2002. Farmer field schools and the future of agricultural extension in Africa. Journal of International Agricultural and Extension Education, 9(2): 29-36 [online]: Available from vtechworks.lib.vt.edu/handle/10919/66004.

Smit MA, Nyirandutiye D, and Weltzien E. 2008. Food consumption study in farming communities in Mali. Report submitted to Improved Nutrition through Staple Foods in Africa (INSTAPA); European Union Project on nutrition in Africa (INSTAPA.org).

Toulmin C. 1986. Access to food, dry season strategies and household size amongst the Bambara of Central Mali. IDS Bulletin, 17(3): 58-66. DOI: 10.1111/j.1759-5436.1986.mp17003009.x

Tuinsma M, Diallo GM, Sidibe CS, Rattunde F, and Lugutuah V. 2011. 10-140, 10-581, 10-582_Year 1 2011_An Be Jigi II: enhancing bioavailability of iron and zinc in varieties of sorghum and pearl millet consumed in Mali [online]: Available from ccrp.org/node/203.

Volti R. 2010. Society and technological change. Worth Publishers, New York, New York. 
Wallendorf M, and Reilly MD. 1983. Ethnic migration, assimilation, and consumption. Journal of Consumer Research, 10(3): 292-302. DOI: 10.1086/208968

Weltzien E, Kanouté M, Toure A, Rattunde F, Diallo B, Sissoko I, et al. 2008. Sélection participative des variétés de sorgho à l'aide d'essais multilocaux dans deux zones cibles. Cahiers Agricultures, 17: 134-139. DOI: 10.1684/agr.2008.0192

White D, Dynes M, Rubardt M, Sissoko K, and Stephenson R. 2013. The influence of intrafamilial power on maternal health care in Mali: perspectives of women, men and mothers-in-law. International Perspectives on Sexual and Reproductive Health, 39(2): 58-68. PMID: 23895882 DOI: $10.1363 / 3905813$ 